\title{
Do-It-Yourself Gamified Cognitive Training: Viewpoint
}

Sjors CF van de Weijer ${ }^{1 *}$, BSc, MSc; Mark L Kuijf ${ }^{1^{*}}$, BSc, MSc, PhD, MD; Nienke M de Vries ${ }^{2 *}$, BSc, MSc, PhD; Bastiaan R Bloem ${ }^{2 *}$, BSc, MSc, PhD, MD; Annelien A Duits ${ }^{3 *}$, BSc, MSc, PhD

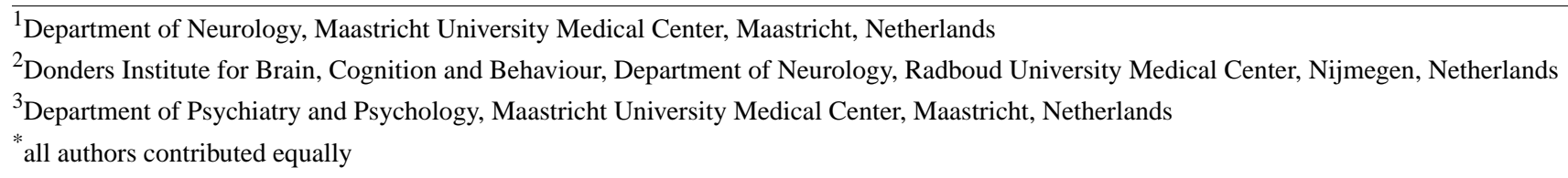

\section{Corresponding Author:}

Sjors CF van de Weijer, BSc, MSc

Department of Neurology

Maastricht University Medical Center

Oxford Building

P Debyelaan 25

Maastricht, $6229 \mathrm{HX}$

Netherlands

Phone: 31626856672

Fax: 31433877055

Email: sjors.vande.weijer@mumc.nl

\begin{abstract}
Cognitive decline is an important nonmotor symptom in Parkinson disease (PD). Unfortunately, very few treatment options are available. Recent research pointed to small positive effects of nonpharmacological cognitive training in PD. Most of these trainings are performed under supervision and solely computerized versions of (traditional) paper-pencil cognitive training programs, lacking rewarding gamification stimulants that could help to promote adherence. By describing 3 different self-invented ways of cognitive gaming in patients with PD, we aimed to raise awareness for the potential of gamified cognitive training in PD patients. In addition, we hoped to inspire the readers with our case descriptions, highlighting the importance of both personalization and cocreation in the development of games for health. In this viewpoint, we have presented 3 PD patients with different ages, with different disease stages, and from various backgrounds, who all used self-invented cognitive training, including elements of personalization and gamification. To indicate generalization into a larger PD population, the recruitment results from a recent cognitive game trial are added. The presented cases show similarities in terms of awareness of their cognitive decline and the ways this process could potentially be counteracted, by looking for tools to train their cognition. On the basis of the response of the recruitment procedure, there seems to be interest in gamified cognitive training in a larger PD population too. Gamification may add to traditional therapies in terms of personalization and adherence. Positive results have already been found with gamified trainings in other populations, and the cases described here suggest that PD is also an attractive area to develop and test gamified cognitive trainings. However, no results of gamified cognitive trainings in PD have been published to date. This suggests an unmet need in this area and may justify the development of gamified cognitive training and its evaluation, for which our considerations can be used.
\end{abstract}

(JMIR Serious Games 2019;7(2):e12130) doi: $\underline{\text { 10.2196/12130 }}$

\section{KEYWORDS}

cognitive remediation; Parkinson disease; video games

\section{Introduction}

\section{Background}

Parkinson disease (PD) is a neurodegenerative disorder characterized by both motor and nonmotor symptoms. Mild cognitive impairment can already be present in up to $40 \%$ of newly diagnosed PD patients [1] and more marked decline can ultimately be seen in up to $83 \%$ of patients [2]. Cognitive impairment is associated with a decreased quality of life, an increased caregiver burden, and an increased risk of developing dementia [3]. Unfortunately, very few treatment options are available. The only effective pharmacological treatment (rivastigmine) provides limited improvements in memory and 
language [4]. Recent research has pointed to small positive effects of nonpharmacological cognitive trainings on working memory, processing speed, and executive function [5-7], suggesting that these interventions could possibly attenuate cognitive deficits in PD. Many of the investigated cognitive trainings in PD are performed under supervision and include solely computerized versions of paper-pencil (traditional) cognitive trainings. These traditional cognitive trainings involve repetitive execution of cognitive tasks but lack gamification stimulants. Gamification of cognitive training can be used to promote adherence, such as reward and engagement, and could eventually improve health outcomes. Both personalization and gamification could increase the adherence to and effectiveness of cognitive training in PD. Although some previously investigated interventions adapted to the user performance, adherence variables were unfortunately insufficiently reported across these studies. Therefore, we are currently unable to conclude that gamification of cognitive training is indeed more attractive for PD patients and results in increased adherence rates. Hence, more research is needed in the area of gamified cognitive training. Before we can test the effectiveness of such gamified cognitive trainings, it would be helpful to explore whether PD patients are interested in using gamified cognitive trainings at all.

\section{Objectives}

In this viewpoint, we have presented 3 independent histories of PD patients with different ages, with different disease stages, and from various backgrounds, who all used self-invented cognitive training that included elements of personalization and gamification. Using computer videogames, card games, or real-life routines, these patients self-trained their cognitive abilities, which are essential for activities of daily living. We will discuss the training types and present the similarities and differences between these cases. We additionally report on recruitment data from a recent gamified cognitive training trial [8]. By describing 3 different self-invented ways of cognitive gaming in patients with PD, we aimed to raise awareness for the potential of gamified cognitive training in PD patients. In addition, we hoped to inspire the readers with our case descriptions, highlighting the importance of both personalization and cocreation in the development of games for health. Finally, we have presented some considerations for future gamified cognitive training development and evaluation.

\section{Cases}

\section{Case 1}

This 64-year-old man with PD had a disease duration of 20 years and a Hoehn and Yahr Stage of III, indicating a mild-to-moderate bilateral disease and some postural instability but being physically independent (the range according to the Hoehn and Yahr stages is from 0 [no symptoms] to V [severely disabled and wheelchair bound]) [9]. In the course of his disease, he started experiencing postural instability, decreased memory performance, and depressive symptoms. His passion was virtual car racing, and he customized a computer videogame racing simulator (called iRacing, by iRacing.com Motorsport Simulations) with a trajectory on the Nürburgring Nordschleife circuit (Germany; see Figure 1 and Multimedia Appendix 1). At the time, he was treated with a levodopa equivalent daily dose of $1285 \mathrm{mg}$, including a daily dose of $3 \mathrm{mg}$ Ropinirole dopamine agonist. He started racing on a daily basis in his simulator and challenged himself to improve on every race lap. He assessed his performance by remembering the influence of variances in turns on lap times. A race simulator challenges various cognitive functions (attention, decision making, and memory) as well as motor functions (reaction times and perceptuomotor skills). In the following months, he experienced improved driving skills in real life and better attentional performance while driving a real car, outside of the simulator. The patient's spouse believed her partner had an extended attentional span after playing the game regularly. His compliance was excellent, as the pursuit of the perfect race lap on the circuit was an intrinsic motivation for creating a gamified cognitive training task. He feels that pushing the boundaries prevents a rapid cognitive decline, and he has now faithfully used his simulator for over 5 years.

Figure 1. Screenshot of the racing simulator game played by Case 1.

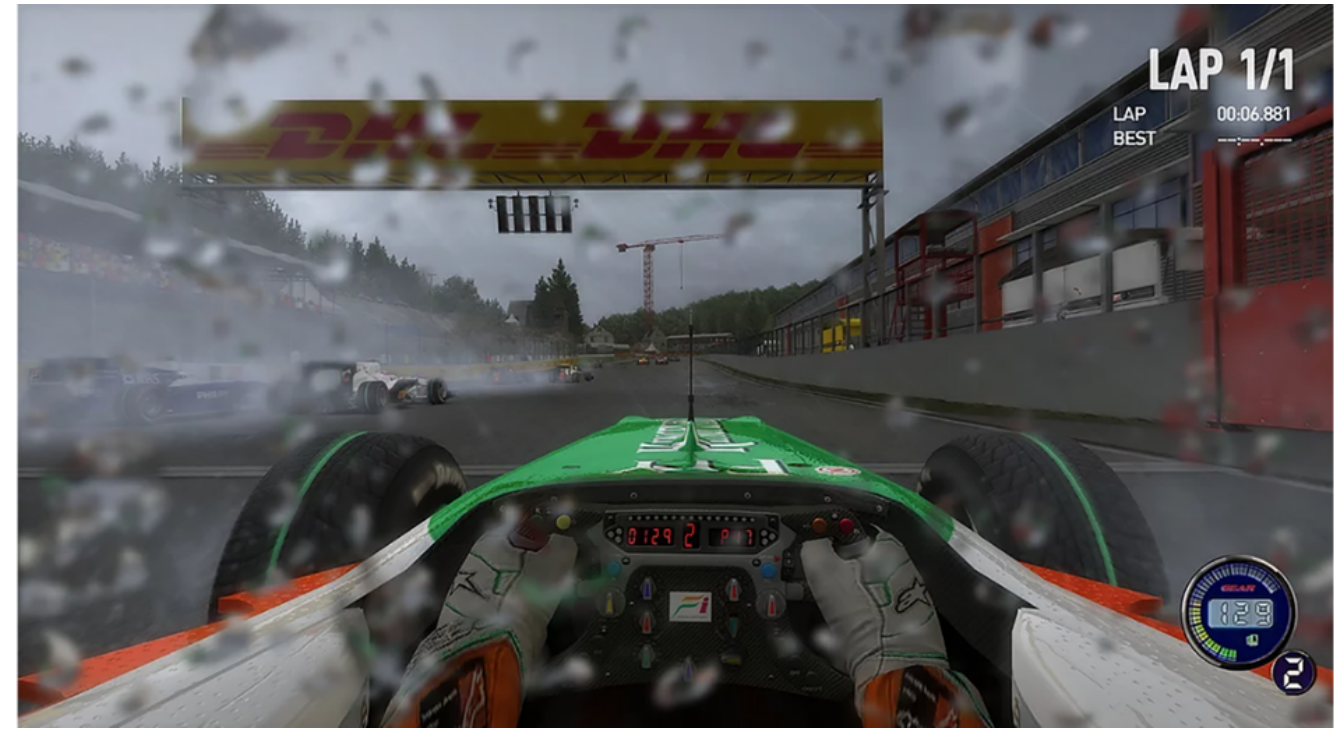




\section{Case 2}

The second case is a 67-year-old woman with PD in Hoehn and Yahr Stage II (bilateral involvement without impairment of balance) and a disease duration of 12 years. Soon after retiring as a financial consultant in the field of education, she became afraid that the decreased working load on her brain would result in memory loss. A few years into the disease, she indeed started experiencing memory loss, which motivated her to train herself in daily real-life situations. Specifically, she has developed several daily routines to train her memory. After waking up, she tries to remember all meetings for the upcoming day. She, afterward, checks her calendar to see if she was right. Also, if she is outdoors and plans a new meeting with a friend, she will note it in her calendar only by the time she comes home. Afterward, she will check to see if she remembered the correct date and time. Also, she manually enters frequently used phone numbers, even though she has saved them as contacts in her smartphone. Furthermore, when she plans on shopping for groceries, she makes a shopping list on paper that includes all the needed ingredients. In the store, however, she will not consult this list, but instead she will buy all products from memory. The shopping list is ultimately referred to as a checklist for completion. This type of real-life training requires multiple cognitive functions, including planning and memory. The patient feels that these self-invented routines keep her memory stable at an acceptable level. She is now confident that she is able to remember almost anything, and she has never heard from others that she forgot something. Importantly, compliance was again excellent, as she has been using these daily routines for over 5 years now.

\section{Case 3}

The third case is a 68-year-old woman with PD in Hoehn and Yahr Stage III and a disease duration of 10 years. She has been living in South Africa volunteering as a community development worker for 28 years and has raised 5 children. After returning to the Netherlands, she was diagnosed with PD in 2009. In the following years, she started noticing cognitive problems, including concentration and memory deficits. She applied to a Dutch Web-based Bridge game service (called StepBridge, by StepBridge Foundation, see Figure 2), where she could play Bridge against gamers of similar difficulty levels at any time this would fit her schedule. This Bridge game requires several cognitive functions, including attention, reasoning, decision making, and memory. She reports subjective benefits in terms of both concentration and memory, which is also observed by her spouse. Compliance was again outstanding, as she has been playing StepBridge regularly for almost 10 years now.

\section{Generalization of These Cases}

To investigate whether this interest for gamified cognitive training can be generalized to a larger PD population, a recruitment newsletter was sent out which contained information on various PD research projects. Among others, it presented a brief introduction to a randomized controlled trial on the effects of a gamified cognitive training in PD [8], including 2 clickable buttons directed to the recruitment website. The newsletter was sent on April 3, 2017 at 7 pm to 1103 PD patients in the Netherlands. As early as the next morning, 60 patients requested the patient information brochure via the recruitment website. The email was opened by over 800 patients, and the recruitment website traffic increased by over 7 times within a month. In total, $135 \mathrm{PD}$ patients requested the patient information brochure via this single newsletter and 55 patients applied to the study, underlining that a larger population of PD patients may be interested in using structured and gamified ways to train cognition. The results from this study are now being analyzed and, when published, may add to the current evidence for the effectivity of gamified cognitive training.

Figure 2. Screenshot of the StepBridge game played by Case 3 .

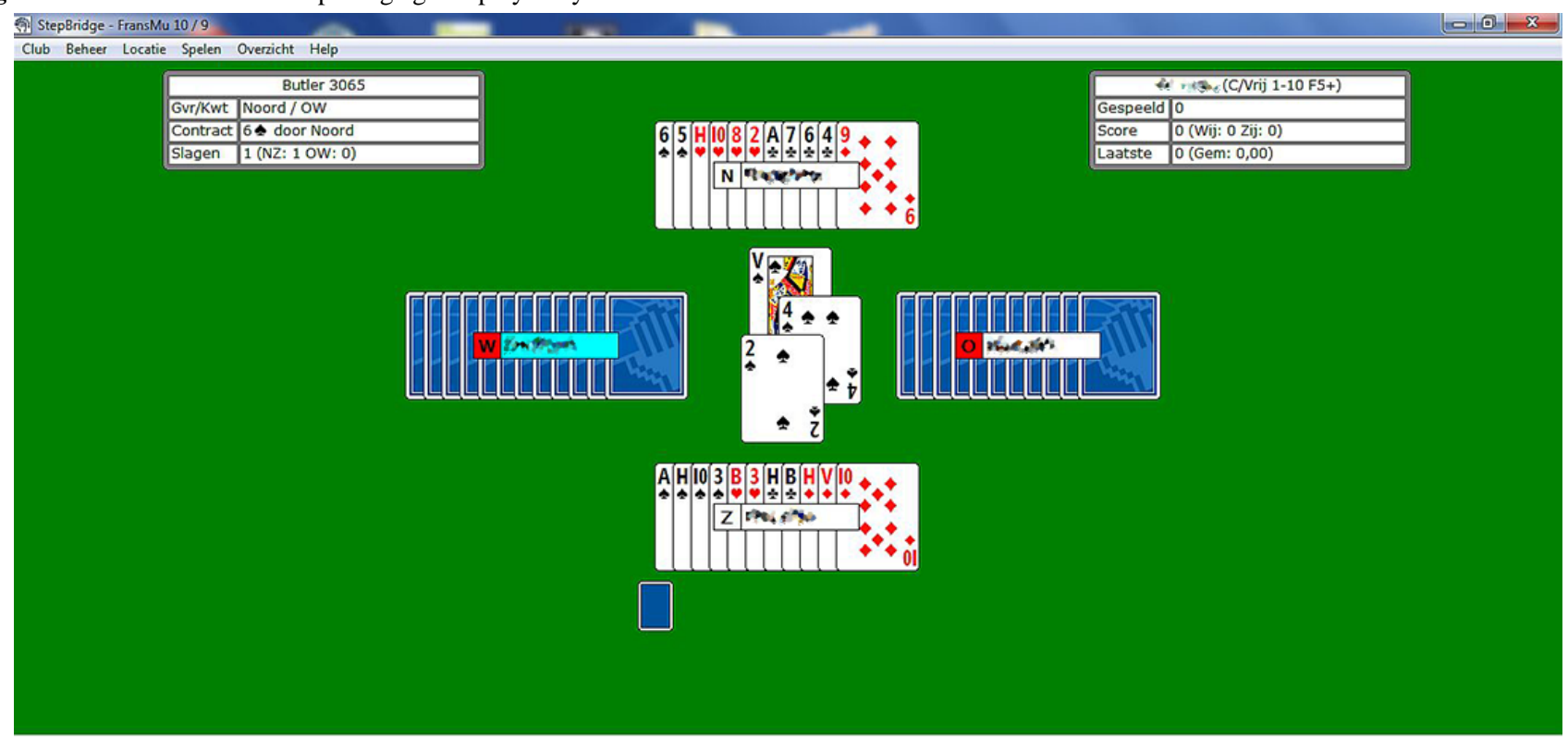




\section{Discussion}

\section{Principal Findings}

The 3 patients presented here are, despite their differences in key characteristics such as age, gender, disease status, and disease duration, also similar in many ways. First, all 3 patients were aware of their decreased cognitive abilities and were proactively looking for ways to potentially counteract their imminent cognitive decline. They challenged themselves with self-invented trainings to improve their own daily life functioning. The first patient used a computer videogame race simulation to train his real-life driving skills. The second patient does not rely on lists to remember meetings or phone numbers, and thereby trains her memory performance for a variety of everyday functions such as shopping. The third patient used an online bridge game to train her concentration and memory performance. Taken together, these 3 stories carefully suggest that at least some PD patients are trying to counteract their cognitive deficits with self-invented trainings that address various cognitive skills. Whether such interventions are actually effective requires further formal testing in controlled studies.

Second, all 3 patients incorporated a form of play to address their cognitive deficits. Although the second patient did not resort to a game, the self-invented training approaches of all 3 patients entailed gamified elements (goals, challenges, and reward systems), which likely add motivation to continue the training. The first patient challenges himself to drive faster and faster laps, the second patient is rewarded each time she remembers the grocery list correctly, and the third patient has the goal to win as many tricks as possible. Indeed, in various studies, gamification has been found to increase the motivation and engagement of study subjects [10-12]. Owing to the predictability and repeatability of traditional (nongamified) trainings, eventually patients might get bored, increasing the risk of dropouts $[13,14]$. This could be avoided by challenging patients into performing interventions of varying complexity using attractive, interactive environments. There is debate on the support for gamified training and a large percentage of the general elderly population has never played game interventions [15], but it is unclear whether this is due to a lack of interest or if they are unfamiliar with the concept of gamified training. In exergaming studies, in the field of PD, it has already been established that patients are able to play games, improve their gameplay performance, and, more importantly, enjoy playing exergames $[16,17]$. One specific example was a recent study where gaming elements were used to promote adherence to a home-based exercise intervention; the results showed that PD patients, despite their well-known difficulties to engage in exercise, faithfully adhered to a regime of aerobic exercise at home, precisely as prescribed, namely 3 times a week for 30 min [18]. Also, various researchers suggested that trainings should be personalized by tailoring the intervention to the individuals' rehabilitation needs and performance levels, thereby improving motivation and adherence $[15,16,19]$. All 3 cases presented above likely showed positive attitudes toward gamification and used gamification strategies, such as goal setting, reinforcement, and the capacity to overcome challenges, that have been scientifically proven to promote health behavior change and thereby influence health outcomes [20]. In addition, all 3 cases showed aspects of personalization: they chose their own way of training and made personal adjustments in gameplay or goals within their training.

Finally, all patients showed excellent adherence to the training for prolonged periods of time (several years). They were intrinsically motivated to continue, possibly because they felt that the therapy had a positive effect on their functional performance. An extrinsically motivated person requires an external reward to engage in a particular behavior, whereas intrinsic motivation arises from intrinsically rewarding factors. People may follow a training because it makes them feel better (intrinsic motivation) and feeling better may then have external benefits (extrinsic motivation) [21]. Ultimately, motivated people tend to exercise a behavior that is particularly rewarding to them, which may explain why these 3 patients continued to use their self-invented training for many years. However, Case 1 was treated with dopamine agonists, which could have resulted in increased addictive behavior in PD and thus in more adherence to the training. Nevertheless, motivation is an important influencer of adherence and it should be an important part of future interventions in this area.

\section{Comparison With Prior Work}

All 3 patients found their own way to train their cognition, but the majority of PD patients are not likely to be able to create such self-invented trainings. However, in some patients, there seems to be a need for a structured way of training cognitive functions. Various traditional cognitive trainings have already been investigated in PD, with small-to-moderate symptomatic effects on cognition, mainly on measures of processing speed, working memory, and executive functions [5,22]. These previous studies had short follow-up periods of maximally 3 months. It would be interesting to see whether these symptomatic effects also persist in the long term and whether the progression of cognitive decline could potentially be delayed (ie, a neuroprotective or disease-modifying effect). However, none of the previous studies investigated the long-term effects on cognition in PD. To date, there is no evidence whether gamified cognitive training can suppress (let alone delay the progression of) cognitive impairment in PD. Many of the investigated cognitive trainings in PD are lacking rewarding gamification stimulants that could stimulate adherence and eventually improve health outcomes even more. In addition, many cognitive training studies had methodological challenges, such as the lack of solid sample sizes based on reliable power calculations. Importantly, showing that gamified cognitive training has disease-modifying effects that extend beyond mere symptomatic effects is very difficult and calls for specific study designs to separate temporary symptomatic improvement from a more sustained protective effect on actual progression [23].

Some efforts have been made to create gamified cognitive assessments, which may add benefits over traditional assessments in terms of reducing stress related to the formal assessment situation. These gamified assessments are usually relatively simple puzzles with, for example, added sound effects to appear as a game. More importantly, they validate well against traditional cognitive assessments [13]. Gamified 
cognitive assessments can additionally be used to evaluate the performance and adjust the game's difficulty level accordingly [8]. To our knowledge, no fully gamified cognitive assessments have been investigated in PD to date.

\section{Theoretical Bases}

Some theoretical bases have been proposed which promote health behavior when used in gamified treatments [24]. According to the self-determination theory, for example, it is assumed that everyone is driven by autonomy, competence, and relatedness [25]. Within games, autonomy can be implemented via features such as choice and structured reward systems, competence can be implemented via personalized challenges and feedback, and relatedness can be implemented via social elements [24]. For gamified treatments in PD patients, the complexity of the apathy-reward-motivation system must also be recognized [26]. Although the exact relationship is not yet clear, apathy is thought to result from dopaminergic depletion in the ventral striatum, substantia nigra, and ventral tegmental area [26]. Indeed, PD patients have a decreased reward sensitivity in an off-dopaminergic medication state [27]. Personalized trainings, with more rewarding elements and interventions that are specifically tailored to their cognitive abilities, will likely improve the self-efficacy of patients. Patients then feel more in control over the events or behaviors with regard to the training, thereby increasing motivation and enhancing resilience to failure [28]. To increase treatment adherence, a potentially ideal cognitive intervention should contain a mix of training elements targeting various cognitive domains but also contain gamified elements. In addition, it is suggested that a personalized challenge level may result in more engagement in the game [29]. Within PD, some computerized cognitive trainings have been investigated, such as RehaCom (computer-assisted cognitive rehabilitation) [30], SmartBrain (28 computerized cognitive exercises) [31], NEUROvitalis (computerized exercises training attention, memory, and executive functions) [32], and InSight (5 exercises training information processing speed) [33], but none of these trainings incorporated gamification or personalization. In other populations, positive effects have been found with health games. For example, the NeuroRacer [34], a game-like training that aims to reduce susceptibility to cognitive interference and adapts the difficulty level to the player's performance levels (personalization), showed positive effects on attention, impulsivity, and multitasking in elderly subjects. Recently, positive results were published for the Project: Evo health game that targets cognitive conditions in children with attention deficit hyperactivity disorder (ADHD) [35]. Although Project: Evo is actually a therapy targeting specific neural circuitries involved in attentional control, the intervention feels like a videogame when it is being performed. The researchers found improvements in working memory and attention, but the treatment was also an attractive way to address ADHD, which is promising when it comes to achieving sustained treatment efficacy over time.

\section{Recommendations for Future Gamified Interventions}

In Table 1, we briefly summarize considerations considering the design and evaluation of future gamified cognitive trainings. This table is based on recommendations from the literature on both game development and evaluation guidelines [36]. 
Table 1. Considerations for developing future gamified cognitive trainings.

\begin{tabular}{|c|c|}
\hline Area and consideration ${ }^{\mathrm{a}}$ & Type \\
\hline \multicolumn{2}{|l|}{ Gameplay } \\
\hline Adopt levels of increasing complexity (with achievable goals) & Gameplay \\
\hline Introduce cognitively demanding aspects slowly & Gameplay \\
\hline Clear user-interface design (large fonts, bright colors) & User-interface \\
\hline Include a dynamic difficulty adaptation mechanism (interactive) & Personalization \\
\hline Personalize training content to individual needs in real-time & Personalization \\
\hline Add social elements (eg, play with grandchildren) & Social functions \\
\hline Add competitive elements (against oneself, computer, or others) & Social functions \\
\hline Choose actions that are familiar to patients (daily activities) & Gameplay \\
\hline Think about fun factors (appealing story, graphics, and sounds) & Gameplay \\
\hline Set long-term goals to help sustain long-term engagement & Engagement \\
\hline Provide in-game variance (keep game engaging for longer periods) & Engagement \\
\hline Reinforce positive performance with visual/audio feedback (reward) & Feedback \\
\hline Avoid negative feedback & Feedback \\
\hline Be hesitant with negative progress reports (self-monitoring) & Feedback \\
\hline \multicolumn{2}{|l|}{ Development } \\
\hline Integrate validated theories (eg, self-determination, motivation) & Design \\
\hline Use recent serious game development guidelines [36] & Design \\
\hline Participate with Parkinson disease patients and professionals in design/evaluation & Design \\
\hline Optionally add other neuroplasticity stimulants (eg, exercise) & Design \\
\hline (Re)evaluate the game with an evaluation protocol [36] & Evaluation \\
\hline \multicolumn{2}{|l|}{ Procedural } \\
\hline Provide crystal-clear and guided instructions & Instructions \\
\hline Guide the patient through the first level(s) & Instructions \\
\hline Set clear goals (distinguish game targets vs training targets) & Instructions \\
\hline Adopt cross-platform availability and plug-and-play technology & Availability \\
\hline Optionally add group-based, therapist-guided booster sessions & Efficacy \\
\hline \multicolumn{2}{|l|}{ Methodological } \\
\hline Clearly describe the training to aid in replication (publication) & Epidemiology \\
\hline Compare standardized versus personalized training & Epidemiology \\
\hline Have a solid sample size & Epidemiology \\
\hline $\begin{array}{l}\text { Report standard measures of disease severity (Hoehn \& Yahr Scale, Unified Parkinson's Disease Rating } \\
\text { Scale Part III) }\end{array}$ & Epidemiology \\
\hline Report standard measures of medication status (Levodopa equivalent daily dosage) & Epidemiology \\
\hline Report standard measures of cognitive status (Montreal Cognitive Assessment, Mini Mental State Exam) & Epidemiology \\
\hline Report objective and subjective measures of safety & Epidemiology \\
\hline Report measures of feasibility and adherence & Epidemiology \\
\hline
\end{tabular}

${ }^{\mathrm{a}}$ Noncomprehensive considerations for gamified cognitive training design (in the field of Parkinson disease); not presented in order of priority and obtained from the wider literature [7,13,15,16,19,20,30,36-39].

\section{Conclusions}

Taken together, the 3 patients presented here as well as the recruitment results from a gamified and personalized cognitive training trial [8] may justify the development of more structured ways of training cognitive functions in $\mathrm{PD}$, while incorporating elements to increase adherence such as personalization and gamification. Positive results have already been found with 
gamified trainings in other populations, and the cases described here suggest that PD is also an attractive area to develop and test gamified cognitive trainings. Our 3 patients also demonstrate enormous creativity and laudable resilience despite having PD. However, the majority of PD patients are not likely to be able to create such self-invented trainings. Researchers, health professionals, patients, and the industry should therefore collaborate to develop motivating and targeted cognitive trainings for persons with $\mathrm{PD}$, for which our considerations offered here can be used. The first steps in this direction have already been taken, and several trials are now ongoing $[8,18,40,41]$.

\section{Conflicts of Interest}

None declared.

\section{Multimedia Appendix 1}

Short clip of Case 1 training in the racing simulator game.

[MP4 File (MP4 Video), 30MB-Multimedia Appendix 1]

\section{References}

1. Yarnall AJ, Breen DP, Duncan GW, Khoo TK, Coleman SY, Firbank MJ, ICICLE-PD Study Group. Characterizing mild cognitive impairment in incident Parkinson disease: the ICICLE-PD study. Neurology 2014 Jan 28;82(4):308-316 [FREE Full text] [doi: 10.1212/WNL.0000000000000066] [Medline: 24363137]

2. Hely MA, Reid WG, Adena MA, Halliday GM, Morris JG. The Sydney multicenter study of Parkinson's disease: the inevitability of dementia at 20 years. Mov Disord 2008 Apr 30;23(6):837-844. [doi: 10.1002/mds.21956] [Medline: $\underline{18307261]}$

3. Aarsland D, Kurz MW. The epidemiology of dementia associated with Parkinson's disease. Brain Pathol 2010 May;20(3):633-639. [doi: 10.1111/j.1750-3639.2009.00369.x] [Medline: 20522088]

4. Schmitt FA, Aarsland D, Brønnick KS, Meng X, Tekin S, Olin JT. Evaluating rivastigmine in mild-to-moderate Parkinson's disease dementia using ADAS-cog items. Am J Alzheimers Dis Other Demen 2010 Aug;25(5):407-413. [doi: 10.1177/1533317510367486] [Medline: 20392860]

5. Leung IH, Walton CC, Hallock H, Lewis SJ, Valenzuela M, Lampit A. Cognitive training in Parkinson disease: a systematic review and meta-analysis. Neurology 2015 Nov 24;85(21):1843-1851 [FREE Full text] [doi: 10.1212/WNL.0000000000002145] [Medline: 26519540]

6. Kalbe E, Folkerts A. [Cognitive training in Parkinson's disease - a new therapy option?]. Fortschr Neurol Psychiatr 2016 Jul;84 Suppl 1:S24-S35. [doi: 10.1055/s-0042-100724] [Medline: 27192506]

7. Walton CC, Naismith SL, Lampit A, Mowszowski L, Lewis SJ. Cognitive training in Parkinson's disease. Neurorehabil Neural Repair 2017 Dec;31(3):207-216. [doi: 10.1177/1545968316680489] [Medline: 27899737]

8. van de Weijer SCF, Duits AA, Bloem BR, Kessels RP, Jansen JF, Köhler S, et al. The Parkin'Play study: protocol of a phase II randomized controlled trial to assess the effects of a health game on cognition in Parkinson's disease. BMC Neurol 2016 Nov 3;16(1):209 [FREE Full text] [doi: 10.1186/s12883-016-0731-z] [Medline: 27809791]

9. Hoehn MM, Yahr MD. Parkinsonism: onset, progression and mortality. Neurology 1967 May;17(5):427-442. [doi: 10.1212/01.wnl.0000405146.06300] [Medline: 6067254]

10. Prins PJM, Dovis S, Ponsioen A, ten Brink E, van der Oord S. Does computerized working memory training with game elements enhance motivation and training efficacy in children with ADHD? Cyberpsychol Behav Soc Netw 2011 Mar;14(3):115-122. [doi: 10.1089/cyber.2009.0206] [Medline: 20649448]

11. Brown HR, Zeidman P, Smittenaar P, Adams RA, McNab F, Rutledge RB, et al. Crowdsourcing for cognitive science--the utility of smartphones. PLoS One 2014;9(7):e100662 [FREE Full text] [doi: 10.1371/journal.pone.0100662] [Medline: 25025865]

12. Aalbers T, Baars MA, olde Rikkert MG, Kessels RP. Puzzling with online games (BAM-COG): reliability, validity, and feasibility of an online self-monitor for cognitive performance in aging adults. J Med Internet Res 2013;15(12):e270 [FREE Full text] [doi: 10.2196/jmir.2860] [Medline: 24300212]

13. Lumsden J, Edwards EA, Lawrence NS, Coyle D, Munafò MR. Gamification of cognitive assessment and cognitive training: a systematic review of applications and efficacy. JMIR Serious Games 2016;4(2):e11 [FREE Full text] [doi: 10.2196/games.5888] [Medline: 27421244]

14. Pachoulakis I, Papadopoulos N, Analyti A. Kinect-based exergames tailored to Parkinson patients. Int J Comput Games Technol 2018 Oct 30;30(4):14 [FREE Full text]

15. Tobaigy A, Alshehri MA, Timmons S, Helal OF. The feasibility of using exergames as a rehabilitation tool: the attitudes, awareness, opinions and experiences of physiotherapists, and older people towards exergames. J Phys Ther Sci 2018 Apr;30(4):555-562. [doi: 10.1589/jpts.30.555] [Medline: 29706705]

16. Barry G, Galna B, Rochester L. The role of exergaming in Parkinson's disease rehabilitation: a systematic review of the evidence. J Neuroeng Rehabil 2014 Mar 7;11:33 [FREE Full text] [doi: 10.1186/1743-0003-11-33] [Medline: 24602325] 
17. Pompeu JE, Mendes FA, Silva KG, Lobo AM, Oliveira TD, Zomignani AP, et al. Effect of Nintendo Wii ${ }^{\mathrm{TM}}$-based motor and cognitive training on activities of daily living in patients with Parkinson's disease: a randomised clinical trial. Physiotherapy 2012 Sep;98(3):196-204. [doi: 10.1016/j.physio.2012.06.004] [Medline: 22898575]

18. van der Kolk NM, de Vries NM, Penko AL, van der Vlugt M, Mulder AA, Post B, et al. A remotely supervised home-based aerobic exercise programme is feasible for patients with Parkinson's disease: results of a small randomised feasibility trial. J Neurol Neurosurg Psychiatry 2018 Sep;89(9):1003-1005. [doi: 10.1136/jnnp-2017-315728] [Medline: 28607121]

19. Keshner EA. Virtual reality and physical rehabilitation: a new toy or a new research and rehabilitation tool? J Neuroeng Rehabil 2004 Dec 3;1(1):8 [FREE Full text] [doi: 10.1186/1743-0003-1-8] [Medline: 15679943]

20. Cugelman B. Gamification: what it is and why it matters to digital health behavior change developers. JMIR Serious Games 2013;1(1):e3 [FREE Full text] [doi: 10.2196/games.3139] [Medline: 25658754]

21. Medalia A, Saperstein A. The role of motivation for treatment success. Schizophr Bull 2011 Sep;37(Suppl 2):S122-S128 [FREE Full text] [doi: 10.1093/schbul/sbr063] [Medline: 21860041]

22. Glizer D, MacDonald PA. Cognitive training in Parkinson's disease: a review of studies from 2000 to 2014. Parkinsons Dis 2016;2016:9291713 [FREE Full text] [doi: 10.1155/2016/9291713] [Medline: 27688923]

23. McGhee DJ, Ritchie CW, Zajicek JP, Counsell CE. A review of clinical trial designs used to detect a disease-modifying effect of drug therapy in Alzheimer's disease and Parkinson's disease. BMC Neurol 2016 Jun 16;16:92 [FREE Full text] [doi: 10.1186/s12883-016-0606-3] [Medline: 27312378]

24. Mühlhaus J, Frieg H, Bilda K, Ritterfeld U. Game-Based Speech Rehabilitation for People with Parkinson's Disease. 2017 May 17 Presented at: UAHCI 2017; July 9-14, 2017; Vancouver, BC, Canada p. 76-85 URL: https://link.springer.com/ chapter/10.1007\%2F978-3-319-58700-4 7 [doi: 10.1007/978-3-319-58700-4 7]

25. Ryan R, Patrick H, Deci E, Williams G. Facilitating health behaviour change and its maintenance: interventions based on self-determination theory. Health Psychol Rev 2008 Mar;10(1):2-5 [FREE Full text]

26. den Brok MG, van Dalen JW, van Gool WA, Moll van Charante EP, de Bie RM, Richard E. Apathy in Parkinson's disease: a systematic review and meta-analysis. Mov Disord 2015 May;30(6):759-769. [doi: 10.1002/mds.26208] [Medline: 25787145]

27. Muhammed K, Manohar S, Ben YM, Chong TT, Tofaris G, Lennox G, et al. Reward sensitivity deficits modulated by dopamine are associated with apathy in Parkinson's disease. Brain 2016 Dec;139(Pt 10):2706-2721 [FREE Full text] [doi: 10.1093/brain/aww188] [Medline: 27452600]

28. Esposito F, Gendolla GH, van der Linden M. Are self-efficacy beliefs and subjective task demand related to apathy in aging? Aging Ment Health 2014 May;18(4):521-530. [doi: 10.1080/13607863.2013.856865] [Medline: 24286481]

29. Csikszentmihalyi M. [Flow: Psychology of the Optimal Experience]. Amsterdam: Boom Publishers Amsterdam; Oct 2008.

30. Cerasa A, Gioia MC, Salsone M, Donzuso G, Chiriaco C, Realmuto S, et al. Neurofunctional correlates of attention rehabilitation in Parkinson's disease: an explorative study. Neurol Sci 2014 Aug;35(8):1173-1180. [doi: 10.1007/s10072-014-1666-z] [Medline: 24554416]

31. París AP, Saleta HG, de la Cruz CM, Silvestre E, Freixa MG, Torrellas CP, et al. Blind randomized controlled study of the efficacy of cognitive training in Parkinson's disease. Mov Disord 2011 Jun;26(7):1251-1258. [doi: 10.1002/mds.23688] [Medline: 21442659]

32. Petrelli A, Kaesberg S, Barbe MT, Timmermann L, Fink GR, Kessler J, et al. Effects of cognitive training in Parkinson's disease: a randomized controlled trial. Parkinsonism Relat Disord 2014 Nov;20(11):1196-1202. [doi:

10.1016/j.parkreldis.2014.08.023] [Medline: 25242806]

33. Edwards JD, Hauser RA, O'Connor ML, Valdés EG, Zesiewicz TA, Uc EY. Randomized trial of cognitive speed of processing training in Parkinson disease. Neurology 2013 Oct 8;81(15):1284-1290 [FREE Full text] [doi: 10.1212/WNL.0b013e3182a823ba] [Medline: 24014503]

34. Anguera JA, Boccanfuso J, Rintoul JL, Al-Hashimi O, Faraji F, Janowich J, et al. Video game training enhances cognitive control in older adults. Nature 2013 Sep 5;501(7465):97-101 [FREE Full text] [doi: 10.1038/nature12486] [Medline: $\underline{24005416]}$

35. Davis NO, Bower J, Kollins SH. Proof-of-concept study of an at-home, engaging, digital intervention for pediatric ADHD. PLoS One 2018;13(1):e0189749 [FREE Full text] [doi: 10.1371/journal.pone.0189749] [Medline: 29324745]

36. Idriss M, Tannous H, Istrate D, Perrochon A, Salle JY, Ho Ba Tho MC, et al. Rehabilitation-oriented serious game development and evaluation guidelines for musculoskeletal disorders. JMIR Serious Games 2017 Jul 4;5(3):e14 [FREE Full text] [doi: 10.2196/games.7284] [Medline: 28676468]

37. Paraskevopoulos I, Tsekleves E, Craig C, Whyatt C, Cosmas J. Design guidelines for developing customised serious games for Parkinson's Disease rehabilitation using bespoke game sensors. Entertain Comput 2014 Dec;5(4):413-424. [doi: 10.1016/j.entcom.2014.10.006]

38. Dörrenbächer S, Müller PM, Tröger J, Kray J. Dissociable effects of game elements on motivation and cognition in a task-switching training in middle childhood. Front Psychol 2014;5:1275 [FREE Full text] [doi: 10.3389/fpsyg.2014.01275] [Medline: 25431564]

39. van de Weijer SCF, Hommel A, Bloem B, Nonnekes J, de Vries NM. Promising non-pharmacological therapies in PD: targeting late stage disease and the role of computer based cognitive training. Parkinsonism Relat Disord 2018 Jan;46(Suppl 1):S42-S46. [doi: 10.1016/j.parkreldis.2017.09.002] [Medline: 28923292] 
40. van der Kolk NM, Overeem S, de Vries NM, Kessels RP, Donders R, Brouwer M, et al. Design of the Park-in-Shape study: a phase II double blind randomized controlled trial evaluating the effects of exercise on motor and non-motor symptoms in Parkinson's disease. BMC Neurol 2015 Apr 16;15:56 [FREE Full text] [doi: 10.1186/s12883-015-0312-6] [Medline: 25880966]

41. Vriend C, Van Balkom TD. ClinicalTrials.gov. 2016. Cognitive Training in Parkinson Study (cogtips) URL: https:/ /clinicaltrials.gov/ct2/show/NCT02920632 [accessed 2018-09-06] [WebCite Cache ID 72EE6EFbZ]

\section{Abbreviations}

ADHD: attention deficit hyperactivity disorder

PD: Parkinson disease

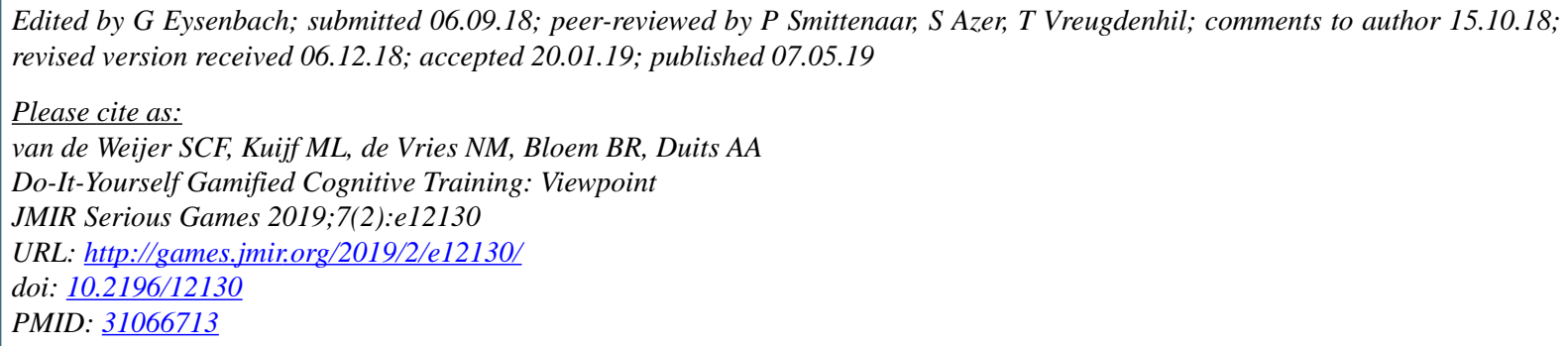

(CSjors CF van de Weijer, Mark L Kuijf, Nienke M de Vries, Bastiaan R Bloem, Annelien A Duits. Originally published in JMIR Serious Games (http://games.jmir.org), 07.05.2019. This is an open-access article distributed under the terms of the Creative Commons Attribution License (https://creativecommons.org/licenses/by/4.0/), which permits unrestricted use, distribution, and reproduction in any medium, provided the original work, first published in JMIR Serious Games, is properly cited. The complete bibliographic information, a link to the original publication on http://games.jmir.org, as well as this copyright and license information must be included. 